\title{
Pre-Enrichment of Estuarine and Fresh Water Environmental Samples with Sodium Chloride Yields in Better Recovery of Vibrio parahaemolyticus
}

\author{
Yoshimitsu Otomo ${ }^{1}$, Farzana Hossain ${ }^{2}$, Fazle Rabbi ${ }^{2}$, Yuki Yakuwa ${ }^{1}$, Chowdhury Rafiqul Ahsan ${ }^{2 *}$ \\ ${ }^{1}$ Division of Medical Life Sciences, Graduate School of Health Sciences, Hirosaki University, Hirosaki, Japan \\ ${ }^{2}$ Department of Microbiology, University of Dhaka, Dhaka, Bangladesh \\ Email: *crahsan@du.ac.bd
}

Received November 24, 2012; revised December 25, 2012; accepted January 26, 2013

\begin{abstract}
Vibrio parahaemolyticus organisms cause acute gastroenteritis in humans. These bacteria are natural inhabitants of both marine and estuarine ecosystems. In the present study, we investigated the effectiveness of a non-selective enrichment of sediment samples with sodium chloride prior to selective enrichment with alkaline peptone water for a better recovery of $V$. parahaemolyticus. Sediment samples were collected with or without $1 \% \mathrm{NaCl}$ from the river Buriganga, located besides Dhaka city and about $400 \mathrm{~km}$ away from the Bay of Bengal, and from the estuary of the river Karnaphuli which flows into the Bay of Bengal. Very small number of $V$. parahaemolyticus ( $<30 \mathrm{MPN} / \mathrm{g}$ ) were detected in the sediments of both river and estuary, where $\mathrm{NaCl}$ was not added. On the other hand, the number of $V$. parahaemolyticus increased to more than 40 times (1500 MPN/g) in the river and 32 times $(960 \mathrm{MPN} / \mathrm{g}$ ) in the estuary where NaCl were added. River sediment sample contained the serotype O9:K41 of $V$. parahaemolyticus and the estuarine sample contained O3:K41 and O3:KUT Our results suggest that a pre-enrichment of environmental samples with $1 \% \mathrm{NaCl}$ helps $V$. parahaemolyticus to survive for at least 7 days until they are enriched with alkaline peptone water, for better recovery.
\end{abstract}

Keywords: Vibrio parahaemolyticus; Sodium Chloride; Estuary; Fresh Water

\section{Introduction}

Vibrio parahaemolyticus is a gram-negative, halophilic bacterium that inhabits in marine environments $[1,2]$. These organisms cause acute gastroenteritis in humans infected through the consumption of raw or inappropriately cooked sea foods [3]. Strains carrying the $t d h$ gene, encoding the thermostable direct hemolysin (TDH), or the trh gene, encoding the TDH-related hemolysin (TRH), or both genes are considered as virulent strains, which can cause the gastroenteritis [2,4-6]. TDH elicits lethal activity in small experimental animals (i.e. production of vascular permeability in rabbit skin; cardiotoxicity; enterotoxicity when tested in the rabbit ileal loop model and mouse lethality) $[7,8]$. TDH is also cytotoxic to various cultured cells and is a pore-forming toxin. Its most extensively studied effect is the ability to cause hemolysis of erythrocytes from different mammalian species [9]. TRH is immunologically related but not identical to TDH. TRH stimulates fluid secretion in the rabbit ileal loop test which suggests a possible role for the toxin in inducing diarrhea [10]. TRH also shows increased rabbit skin vascular permeability and cardiotoxicity on cultured

\footnotetext{
${ }^{*}$ Corresponding author.
}

myocardial cells [11]. Moreover, both TDH and TRH induce chloride secretion in human colonic epithelial cells [12].

Many reports have been published on the isolation of $V$. parahaemolyticus from the environmental sources; most of them are marine or estuarine ecosystems, because of the organisms' indispensable requirement of $\mathrm{NaCl}$ for survival and growth [1,3]. Some researchers have also isolated $V$. parahaemolyticus from water, plankton or sediment samples of fresh water environments [13-15] which may suggest that the habitat of the halophilic V. parahaemolyticus could also be somewhere out of marine environment, where the requirement of $\mathrm{NaCl}$ for growth is probably substituted with some other compounds present in the fresh water $[13,16]$.

Most of the environmental samples are selectively enriched first with alkaline peptone water (APW) and then plated on standard culture media for growth $[17,18]$. APW is the preferred enrichment medium for vibrios including $V$. parahaemolyticus. The high $\mathrm{pH}$ of the medium ( $\mathrm{pH}$ close to 9) and $\mathrm{NaCl}$ concentration inhibit many other bacteria and favor vibrios [19]. The selective enrichment of the marine or estuarine environmental samples with APW has yielded in better recovery of $V$. 
parahaemolyticus $[17,18,20]$. The existing APW method has also been applied to detect $V$. parahaemolyticus in fresh water [20]. However, the isolation schemes have not been carefully studied yet and only enrichment in APW showed insignificant or low rate of isolation of $V$. parahaemolyticus from fresh water than marine water samples [21,22]. Also, a non selective enrichment of bacteria prior to selective enrichment was found to be more effective by researchers in detecting bacteria injured by various environmental stresses [23,24]. All these previous information made us interested to investigate the effectiveness, if any, of a non-selective enrichment of estuarine and fresh water environmental samples with sodium chloride for different periods of time prior to selective enrichment with APW for a better recovery of $V$. parahaemolyticus from those samples. This simple preenrichment with sodium chloride gave better recovery of $V$. parahaemolyticus from both estuarine and fresh water environmental samples, where the fresh water salinity was zero.

\section{Materials and Methods}

\subsection{Study Area and Sample Collection}

Sediment samples (approximately 100 g, 1 - 2 feet from the bank) were collected from two different sites. For fresh water environment, we collected samples from the river Buriganga, located by the side of Dhaka City, which is about $400 \mathrm{~km}$ away from the Bay of Bengal. Other samples were collected from the estuary of the river Karnaphuli, located in Chittagong District, which flows to the Bay of Bengal.

Temperature and salinity of each collection site were recorded. Each $100 \mathrm{~g}$ sediment sample was taken in plastic bags already containing $1 \mathrm{~g}$ of sodium chloride $(\mathrm{NaCl})$ and mixed well, so that the final $\mathrm{NaCl}$ concentration of the sample becomes $1 \%$. Control sediment samples were collected in bags containing no $\mathrm{NaCl}$. All samples were kept at room temperature for 7 days until processed in the laboratory.

\subsection{Estimation of $V$. parahaemolyticus in Sediment Samples}

For the enumeration of $V$. parahaemolyticus in sediment samples, 3-tube 5-dilution Most Probable Number (MPN) method was used as described previously [25] with modification by Hara-Kuda et al., [26]. A $10 \mathrm{~g}$ of sediment sample was homogenized in $90 \mathrm{ml}$ of APW (Nissui Co., Japan) in a stomacher bag and 10, 1, 0.1, 0.01 and 0.001 $\mathrm{ml}$ of the homogenate were inoculated into $10 \mathrm{ml}$ of APW in triplicate and incubated at $35^{\circ} \mathrm{C}$ to $37^{\circ} \mathrm{C}$ for $18 \mathrm{~h}$. One-milliliter portions of each APW culture were transferred into $10 \mathrm{ml}$ of salt polymyxin broth (SPB; Nissui Co., Japan) and incubated at $35^{\circ} \mathrm{C}$ to $37^{\circ} \mathrm{C}$ for $18 \mathrm{~h}$. Next,
$1 \mathrm{ml}$ of the SPB culture was inoculated into $10 \mathrm{ml}$ of fresh SPB and incubated for $35^{\circ} \mathrm{C}$ to $37^{\circ} \mathrm{C}$ for $6 \mathrm{~h}$. Then a loopful of final enrichment culture in SPB was plated onto CHROMagar ${ }^{\mathrm{TM}}$ Vibrio (CV) agar (CHRO-Magar, France). After incubation for $18 \mathrm{~h}$ at $37^{\circ} \mathrm{C}$, purple colonies on the $\mathrm{CV}$ agar plates were picked and subjected to standard biochemical tests for the identification of $V$. parahaemolyticus. The biochemical media used were triple sugar iron medium (TSI; Eiken Co, Tokyo, Japan), lysine-indole-motility medium (LIM; Nissui Co., Japan), and $1 \%$ of polypeptone broth (Nihon Pharmaceutical Co. Ltd., Japan) supplemented each with $0 \%, 3 \%, 6 \%, 8 \%$, $10 \% \mathrm{NaCl}$. Test strains showing alkaline slant and acid butt reactions in the triple sugar iron medium, positive reactions for lysine decarboxylase production, indole production, motility in the LIM medium, and no growth in $0 \%$ but growth in $3 \%$ to $8 \% \mathrm{NaCl}$, were differentiated as $V$. parahaemolyticus. Finally, the test strains were identified by API-20E test strips (bioMériux, Inc.). Only tubes that confirmed the presence of $V$. parahaemolyticus were considered as positive tubes. The counts were determined from MPN table [25]. V. parahaemolyticus serotype O3:K6 was used as positive control to compare the biochemical characteristics of the test strains.

\subsection{Serogrouping of the Isolated $V$. parahaemolyticus Strains}

Serogrouping of the $V$. parahaemolyticus isolates was done using a commercially available $V$. parahaemolyticus antiserum test kit (Denka Seiken, Tokyo, Japan) by following the manufacturer's instructions. Briefly, the strains were first grown on APW agar containing $3 \% \mathrm{NaCl}$. Following overnight incubation at $37^{\circ} \mathrm{C}$, a loopful of inoculum was mixed with $1 \mathrm{ml}$ normal saline. An aliquot of the cell suspension in normal saline was boiled for $2 \mathrm{~h}$ and used for serotyping, based on the $\mathrm{O}$ antigen used for serotyping, based on the $\mathrm{O}$ antigen. The remaining cell suspension (not boiled) was used for serotyping, based on the $\mathrm{K}$ antigen.

\section{Results}

\subsection{Pre-Enrichment with $\mathrm{NaCl}$ and Quantitative Analysis of $V$. parahaemolyticus in Sediment Samples}

In this study, we investigated the effectiveness of $\mathrm{NaCl}$ pre-enrichment of the estuarine and fresh water sediment samples prior to selective enrichment with APW for a better recovery of the $V$. parahaemolyticus from the sediment samples. Table 1 shows the quantitative and qualitative recoveries of $V$. parahaemolyticus from both estuarine and fresh water sediment samples with or without pre-enrichment with $\mathrm{NaCl}$. Sediment samples from $\mathrm{Bu}-$ riganga river, where the salinity is zero, showed promis- 
ing results. The river sediment sample, which was preenriched with $1 \% \mathrm{NaCl}$, showed much higher MPN value on day 7 (MPN value 1500), when compared with the corresponding control sediment sample, without any $\mathrm{NaCl}$ pre-enrichment. Similar results were also found for the estuary samples, where the salinity was 2.0. Estuarine sediment sample with $\mathrm{NaCl}$ pre-enrichment produced an MPN value of 930 on day 7, where as the corresponding control sediment without any pre-enrichment produced only an MPN value of $<30$. All these results clearly indicate that a pre-enrichment with sodium chloride has profound effect in long time (at least up to 7 days) survival of the organisms in sediment samples of both estuary and river followed by enrichment in APW and recovery.

\subsection{Serotype Distribution of $\boldsymbol{V}$. parahaemolyticus}

$V$. parahaemolyticus was isolated from sediment samples of upstream of river Buringanga and estuary of river Karnaphuli. Pre-enrichment followed by selective enrichement and inoculation on chromogenic agar medium were found to be reliable methods for isolation of $\mathrm{V}$. parahaemolyticus from sediment samples. The two sampling sites examined differed for the isolated serotypes. The serotype 09:K41 was restricted in the river Buriganga whereas O3:K41 and O3:K un-typeable (KUT) were restricted in estuary of river Karnaphuli.

\section{Discussion}

Toxigenic $V$. cholerae $\mathrm{O} 1$ bacteria have been found to survive for extended period in water containing no nutrients [27]. During the reduced nutrient levels, such as those encountered in aquatic environments, $V$. cholerae $\mathrm{O} 1$ undergo physiological and morphological changes $[28,29]$. These changes may be related to viable but not culturable (VBNC) form of $V$. cholerae 01 , which is induced by nutrient deficient environment [30]. In this state, the bacteria retain pathogenicity but their metabolic activities become minimal and they cannot be cultured on standard cultural media [31]. When the growth conditions become more favorable, the organisms can be readily

Table 1. Quantitative and qualitative recoveries of $\boldsymbol{V}$. parahaemolyticus from estuarine and fresh water sediment samples with or without pre-enrichment with sodium chloride.

\begin{tabular}{cccc}
\hline Sample site & $\begin{array}{c}\text { Pre-enrichment } \\
\text { with NaCl }\end{array}$ & $\begin{array}{c}\text { MPN/g sediment } \\
\text { on day 7 }\end{array}$ & Serotype \\
\hline $\begin{array}{c}\text { Buriganga } \\
\text { river }\end{array}$ & + & 1500 & O9:K41 \\
& - & $<30$ & O9:K41 \\
Karnaphuli & + & 930 & O3:K41 \\
estuary & - & $<30$ & O3:KUT \\
& & & None \\
\hline
\end{tabular}

+done; "not done. revived [32]. This is probably why we enrich the environmental samples before we put them into standard cultural media for growth. Again, this might depend on the Vibrio species and salinity of the environment from where the organisms are isolated. It has been found that, $V$. parahaemolyticus, V. alginolyticus and V. fluvialis, species that tolerate higher salt concentrations are isolated from sites with high salinity. On the other hand, the study sites with much lower salinity, yielded almost exclusively $V$. cholerae, the species which prefer lower salinity [33]. Therefore, for V. parahaemolyticus, we need to take extra care in the initial isolation, especially when the sampling site is a fresh water environment and a preenrichment with sodium chloride probably helped them survive in the environment out of its natural habitat.

Recently, Schets et al., [20] reported the growth of different environmental Vibrio species using a culture method that included enrichments of the samples in alkaline buffered peptone water (ABPW) prior to cultivation on thiosulphate citrate bile sucrose (TCBS) agar. Enrichment steps included incubation in ABPW or ABPW without $\mathrm{NaCl}$, at different temperatures and time periods. It was found that $V$. parahaemolyticus could only be isolated from enrichment culture and not from those grown in ABPW without sodium chloride. Our results support this recent findings and additionally suggest that a pre-enrichment of environmental samples with $1 \% \mathrm{NaCl}$ helps the $V$. parahaemolyticus to survive for at least 7 days until they are enriched with alkaline peptone water in the laboratory for further growth.

In a previous study, we compared the survivability of the $V$. cholerae $\mathrm{O} 1$ organisms in artificial microcosms under different stressed conditions, such as salinity, $\mathrm{pH}$ and temperature, for different periods of time [34]. It was found that at $0 \%$ salinity, neutral $\mathrm{pH}$ and at $37^{\circ} \mathrm{C}, V$. cholerae $\mathrm{O} 1 \mathrm{El-Tor}$ Ogawa biotype undergoes to VBNC state 5 days after the incubation period and could not be grown on standard culture media. In this study, we also observed similar results. The Buriganga river sediment sample, without any pre-enrichment with $\mathrm{NaCl}$, obtained an MPN value of $<30$ after 7 days (Table 1). Here the cells had probably undergone to the VBNC state and could not be recovered on culture plates. However, the same sample, when pre-enriched with $1 \% \mathrm{NaCl}$, showed an MPN value of 1500 after 7 days of incubation at room temperature. All these data strongly suggest that a $1 \%$ $\mathrm{NaCl}$ pre-enrichment of the environmental samples, both estuarine and fresh water, helps the $V$. parahaemolyticus to survive and can later be cultivated on standard culture media. In addition, it was found that river sediment sample contained the serotype O9:K41 of $V$. parahaemolyticus and the estuarine sample contained O3:K41 and O3:KUT. We are now investigating other environmental factors, if any, which help the $V$. parahaemolyticus to 
survive in stressed environmental conditions.

\section{Acknowledgements}

This work was partially supported by KAKENHI, Grantsin-Aid for Scientific Research (B-22406003), Japan.

\section{REFERENCES}

[1] M. Nishibuchi and J. B. Kaper, "Thermostable Direct Hemolysin Gene of Vibrio parahaemolyticus: A Virulence Gene Acquired by a Marine Bacterium," Infection and Immunity, Vol. 63, No. 6, 1995, pp. 2093-2099.

[2] R. Sakazaki, K. Tamura, T. Kato, Y. Obara and S. Yamai, "Studies on the Enteropathogenic, Facultatively Halophilic Bacteria, Vibrio parahaemolyticus III Enteropathogenicity,” Japanese Journal of Medical Science and Biology, Vol. 21, No. 5, 1968, pp. 325-331.

[3] M. Nishibuchi, “Vibrio parahaemolyticus,” In: M. D. Miliotis and J. W. Bier, Eds., International Handbook of Foodborne Pathogens, Taylor \& Francis, New York, 2003, pp. 237-252. doi:10.1201/9780203912065.ch15

[4] T. Honda, Y. Ni. and T. Miwatani, "Purification of a TDHRelated Hemolysiproduced by a Kanagawa Phenomenon Negative Clinical Isolate of V. parahaemolyticus O6:K46,” FEMS Microbiology Letters, Vol. 48, No. 2, 1989, pp. 241-246. doi:10.1016/0378-1097(89)90307-8

[5] Y. Miyamoto, T. Kato, Y. Obara, S. Akiyama, K. Takizawa and S. Yamai, "In Vitro Hemolytic Characteristics of Vibrio parahaemolyticus: Its Close Correlation with Human Pathogenicity," Journal of Bacteriology, Vol. 100, No. 2, 1969, pp. 1147-1149.

[6] J. Tada, N. Ohashi, N. Nishimura, Y. Shirasaki, H. Ozaki, S. Fukushima, J. Takano, M. Nishibuchi and Y. Takeda, "Detection of the Thermostable Direct Hemolysin Gene $(t d h)$ and the Thermostable Direct Hemolysin-Related Hemolysin Gene (trh) of Vibrio parahaemolyticus by Polymerase Chain Reaction," Molecular and Cellular Probes, Vol. 6, No. 6, 1992, pp. 477-487. doi:10.1016/0890-8508(92)90044-X

[7] Y. Takeda, "Thermostable Direct Hemolysin of Vibrio parahaemolyticus," Methods in Enzymology, Vol. 165, 1988, pp. 189-193. doi:10.1016/S0076-6879(88)65029-4

[8] T. Iida and T. Honda, "Hemolysins Produced by Vibrios," Journal of Toxicology-Toxin Reviews, Vol. 16, No. 4, 1997, pp. 215-227. doi:10.3109/15569549709016457

[9] M. Nishibuchi, T. Taniguchi, T. Misawa, V. KhaeomaneeIam, T. Honda and T. Miwatani, "Cloning and Nucleotide Sequence of the Gene (trh) Encoding the Hemolysin Related to the Thermostable Direct Hemolysin of Vibrio parahaemolyticus," Infection and Immunity, Vol. 57, No. 9, 1989, pp. 2691-2697.

[10] T. Honda, Y. Ni and T. Miwatani, "Purification and Characterization of a Hemolysin Produced by a Clinical Isolate of Kanagawa Phenomenon-Negative Vibrio parahaemolyticus and Related to the Thermostable Direct Hemolysin," Infection and Immunity, Vol. 56, No. 4, 1988, pp. 961-965.
[11] T. Honda and I. Iida, "The Pathogenicity of Vibrio parahaemolyticus and the Role of Hemolysins," Reviews in Medical Microbiology, Vol. 4, No. 2, 1993, pp. 106-113. doi:10.1097/00013542-199304000-00006

[12] X.-H. Zhang and B. Austin, "Haemolysins in Vibrio Species,” Journal of Applied Microbiology, Vol. 98, No. 5, 2005, pp. 1011-1019. doi:10.1111/j.1365-2672.2005.02583.x

[13] B. L. Sarkar, G. B. Nair, B. K. Sircar and S. C. Pal, “Incidence and Level of Vibrio parahaemolyticus Associated with Freshwater Plankton,” Applied and Environmental Microbiology, Vol. 46, No. 1, 1983, pp. 288-290.

[14] B. L. Sarkar, G. B. Nair, A. K. Banerjee and S. C. Pal, "Seasonal Distribution of Vibrio parahaemolyticus in Freshwater Environs and in Association with Freshwater Fishes in Calcutta," Applied and Environmental Microbiology, Vol. 49, No. 1, 1985, pp. 132-136.

[15] K. Venkateswaran, T. Takai, I. M. Navarro, H. Nakano, H. Hashimoto and R. J. Siebeling, "Ecology of Vibrio cholerae non-O1 and Salmonella spp. and Role of Zooplankton in Their Seasonal Distribution in Fukuyama Coastal Waters, Japan,” Applied and Environmental Microbiology, Vol. 55, No. 6, 1989, pp. 1591-1598.

[16] Y. Otomo, F. Rabbi, Y. Yakuwa and C. R. Ahsan, "Detection of Vibrio parahaemolyticus in the River Buriganga, Dhaka, Bangladesh,” In: N. Choudhury, C. R. Ahsan, M. M. Karim, Eds., Proceedings of 3rd Bangladesh-Japan Joint International Conference on Food Safety and Hygiene, Bangladesh Academy of Sciences, Dhaka, 2008, pp. 152-162.

[17] M. Alam, W. B. Chowdhury, N. A. Bhuiyan, A. Islam, N. A. Hasan, G. B. Nair, H. Watanabe, A. K. Siddique, A. Huq, R. B. Sack, M. Z. Akhter, C. J. Grim, K. M. Kam, C. K. Luey, H. P. Endtz, A. Cravioto and R. R. Colwell, "Serogroup, Virulence and Genetic Traits of Vibrio parahaemolyticus in the Estuarine Ecosystem of Bangladesh," Applied and Environmental Microbiology, Vol. 75, No. 19, 2009, pp. 6268-6274. doi:10.1128/AEM.00266-09

[18] A. DePaola and M. L. Motes, "Isolation of Vibrio parahaemolyticus from Wild Raccoons in Florida,” In: R. R. Colwell, Ed., Vibrios in the Environment, John Wiley \& Sons, Inc., New York, 1984, pp. 563-566.

[19] B. Gomez-Gil and A. Roque, "Isolation, Enumeration and Preservation of the Vibrionaceae,” In: F. L. Thompson, A. Brian and J. Swings, Eds., The Biology of Vibrios, American Society for Microbiology Press, Washington DC, 2006, pp. 15-26.

[20] F. M. Schets, H. H. van der Berg, A. Marchese, S. Garbom and A. M. de Roda Husman, "Potentially Human Pathogenic Vibrios in Marine and Fresh Bathing Waters Related to Environmental Conditions and Disease Outcome," International Journal of Hygiene and Environmental Health, Vol. 214, No. 5, 2011, pp. 399-406. doi:10.1016/j.ijheh.2011.05.003

[21] K. Venkateswaran, C. Kiiyukia, M. Takaki, H. Nakano, H. Matsuda, H. Kawakami and H. Hashimoto, "Characterization of Toxigenic Vibrios Isolated from the Freshwater Environment of Hiroshima, Japan,” Applied and Environmental Microbiology, Vol. 55, No. 10, 1989, pp. 2613- 
2618.

[22] M. M. Kagiko, W. A. Damiano and M. M. Kayihura, “Characterization of Vibrio parahaemolyticus Isolated from Fish in Kenya," East African Medical Journal, Vol. 78, No. 3, 2001, pp. 124-127. doi:10.4314/eamj.v78i3.9076

[23] L. R. Benchat, "Suitability of Some Enrichment Broths and Dilutions for Enumerating Cold- and Heat-Stressed Vibrio parahaemolyticus," Canadian Journal of Microbiology, Vol. 23, No. 5, 1977, pp. 630-633. doi:10.1139/m77-092

[24] B. Ray, S. M. Hawkin and C. R. Mackney, "Method for the Detection of Injured Vibrio parahaemolyticus in Seafoods,” Applied and Environmental Microbiology, Vol. 35, No. 6, 1978, pp. 1121-1127.

[25] J. T. Peeler, G. A. Houghtby and A. P. Rainosek, "The Most Probable Number Technique,” In: C. Vanderzant and D. F. Splittstoesser, Eds., Compendium of Methods for the Microbiological Examination of Foods, 3rd Edition, American Public Health Association, Washington DC, 1992, pp. 105-120.

[26] Y. Hara-Kudo, K. Sugiyama, M. Nishibuchi, A. Chowdhury, J. Yatsuyanagi, Y. Ohtomo, A. Saito, H. Nagano, T. Nishina, H. Nakawaga, H. Konuma, M. Miyahara, S. Kumagai, "Prevalence of Pandemic Thermostable Direct Hemolysin-Producing Vibrio parahaemolyticus O3:K6 in Seafood and the Coastal Environment in Japan,” Applied and Environmental Microbiology, Vol. 67, No. 12, 2003, pp. 3883-3891. doi:10.1128/AEM.69.7.3883-3891.2003

[27] C. J. Miller, B. Drasar and R. G. Feachem, "Response of Toxigenic Vibrio cholorae O1 to Physiological Stresses in Aquatic Environments," The Journal of Hygiene, Vol.
93, No. 3, 1984, pp. 475-495. doi:10.1017/S0022172400065074

[28] R. Baker, F. Singelton and M. Hood, "Effects of Nutrient Deprivation on Vibrio cholera," Applied and Environmental Microbiology, Vol. 46, No. 4, 1983, pp. 930-940.

[29] J. D. Oliver and W. F. Stringer, "Lipid Composition of a Psychrophilic Marine Vibrio sp. during Starvation-Induced Morphogenesis,” Applied and Environmental Microbiology, Vol. 47, No. 3, 1984, pp. 461-466.

[30] R. R. Colwell, P. R. Brayton, D. J. Grimes, D. R. Roszak, S. A. Huq and L. M. Palmer, "Viable but Non-culturable Vibrio cholerae and Related Environmental Pathogens in the Environment: Implications for Release of Genetically Engineered Microorganisms,” Nature Biotechnology, Vol. 3, 1985, pp. 817-820. doi:10.1038/nbt0985-817

[31] W. Baffone, B. Citterio, E. Vittoria, A. Casaroli, R. Campana, L. Falzano and G. Donelli, "Retention of Virulence in Viable but Non-culturable Halophilic Vibrio spp.,” International Journal of Food Microbiology, Vol. 89, No. 1, 2003, pp. 31-39. doi:10.1016/S0168-1605(03)00102-8

[32] D. B. Roszak and R. R. Colwell, "Survival Strategies of Bacteria in the Natural Environment," Microbiology Reviews, Vol. 51, No. 3, 1987, pp. 365-379.

[33] J. D. Oliver and J. B. Kaper, “Vibrio Species,” In: M. P. Doyle, L. R. Beuchat and T. J. Montville, Eds., Food Microbiology: Fundamentals and Frontiers, ASM Press, Washington DC, 1997, pp. 228-264.

[34] M. M. Haque, S. I. Khan and C. R. Ahsan, "Influence of Some Physicochemical Stresses on the Survival of Vibrio cholerae $\mathrm{O} 1$ at Non-culturable State," Bangladesh Journal of Microbiology, Vol. 24, No. 2, 2007, pp. 133-136. 